\title{
LETTER
}

\section{Noise pollution in the ICU: time to look into the mirror}

\author{
Koen S Simons ${ }^{1,2^{*}}$, Munhum Park ${ }^{3}$, Armin Kohlrausch $^{3}$, Mark van den Boogaard $^{2}$, Peter Pickkers ${ }^{2}$, \\ Werner de Bruijn ${ }^{3}$ and Cornelis PC de Jager ${ }^{1}$
}

See related research by Darbyshire and Young, http://ccforum.com/content/17/5/R187

We read with interest the recent issue of Critical Care in which Darbyshire and Young [1] reported on noise levels in five different ICUs and demonstrated average sound pressure levels far above the World Health Organization recommended standard of $35 \mathrm{~dB} \mathrm{~L}_{\mathrm{Aeq}}$ (A-weighted energy-equivalent sound pressure level in decibels). Although their article provides an interesting insight into the ICU soundscape, the authors did not attempt to investigate the sources of noise. In the literature, only few studies have performed an analysis of noise sources, using either questionnaires [2] or a human observer in the patient's room [3-5]. Aiming to provide more insight into this matter, some of the authors recently performed an acoustic survey in an ICU room in order to determine which sources are responsible for the high noise levels, and details of this study were recently published [6]. Briefly, an audio recording was made by using a calibrated microphone in an ICU room at Jeroen Bosch Hospital for a duration of 67 hours. In addition to the analysis of various acoustic parameters, a 24-hour audio fragment was manually annotated by six research assistants. All sound events $(\mathrm{n}=27,421)$ were identified by using 28 noise source labels, which were grouped into five noise categories.

Acoustic analysis showed an average sound pressure level of $61 \mathrm{~dB} \mathrm{~L}$ Aeq when the room was occupied. In agreement with the aforementioned study, the number of predicted loudness peaks was up to 90 per hour. Restorative periods were defined as periods of at least 5 minutes in which the sound pressure level relative to the background level did not exceed 17.7

\footnotetext{
* Correspondence: k.simons@jbz.nl

'Department of Intensive Care and Emergency Medicine, Jeroen Bosch Ziekenhuis, Henri Dunantstraat 1, 's Hertogenbosch 500 ME, The Netherlands

${ }^{2}$ Department of Intensive Care Medicine, Radboud University Medical Centre, Geert Grooteplein 21, Nijmegen 6500 HB, The Netherlands

Full list of author information is available at the end of the article
}

dBA (A-weighted sound pressure level in decibels); only approximately $46 \%$ of the periods recorded at night were considered to be restorative, and the average duration of these restorative periods was approximately 13 minutes. Source-specific analysis revealed that, on average, noisy events related to staff activities (54 $\left.\mathrm{dB} \mathrm{L}_{\mathrm{Aeq}}\right)$ occurred approximately 10 times per minute, staff speech (55 dB L $\left.\mathrm{L}_{\mathrm{Aeq}}\right)$ occurred approximately 4 times per minute, and alarms $\left(57 \mathrm{~dB} \mathrm{~L}_{\text {Aeq }}\right)$ also occurred approximately 4 times per minute. Further analyses showed that $57 \%$ of total acoustic energy and $92 \%$ of predicted loudness peaks could be attributed to the activities and speech of hospital personnel (Figure 1). We agree with Darbyshire and Young [1] that high sound pressure levels may have detrimental effects in the already vulnerable population of ICU patients. The aforementioned study demonstrates that more than half of all acoustic energy in an ICU is related to human activities and speech and therefore is potentially modifiable. Strategies involving the adaptation of human behavior therefore may prove to be very effective at reducing noise pollution in the ICU.

Abbreviation
$d B L_{\text {Aeq: }}$ : A-weighted energy-equivalent sound pressure level in decibels.

\section{Competing interests}

MP, AK, and WdB are employees of Koninklijke Philips n.v. (Amsterdam, The Netherlands), which provided the recording equipment used in the study described above. KSS, MvdB, PP, and CPCdJ declare that they have no competing interests.

\section{Author details}

'Department of Intensive Care and Emergency Medicine, Jeroen Bosch Ziekenhuis, Henri Dunantstraat 1, 's Hertogenbosch 500 ME, The Netherlands. ${ }^{2}$ Department of Intensive Care Medicine, Radboud University Medical Centre, Geert Grooteplein 21, Nijmegen 6500 HB, The Netherlands. ${ }^{3}$ Smart Sensing \& Analysis Group, Philips Research Laboratories, High Tech Campus 36, Eindhoven 5656 AE, The Netherlands.

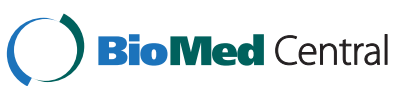

(c) 2014 Simons et al.; licensee BioMed Central Ltd. This is an Open Access article distributed under the terms of the Creative Commons Attribution License (http://creativecommons.org/licenses/by/4.0), which permits unrestricted use, distribution, and reproduction in any medium, provided the original work is properly credited. The Creative Commons Public Domain Dedication waiver (http://creativecommons.org/publicdomain/zero/1.0/) applies to the data made available in this article, unless otherwise stated. 


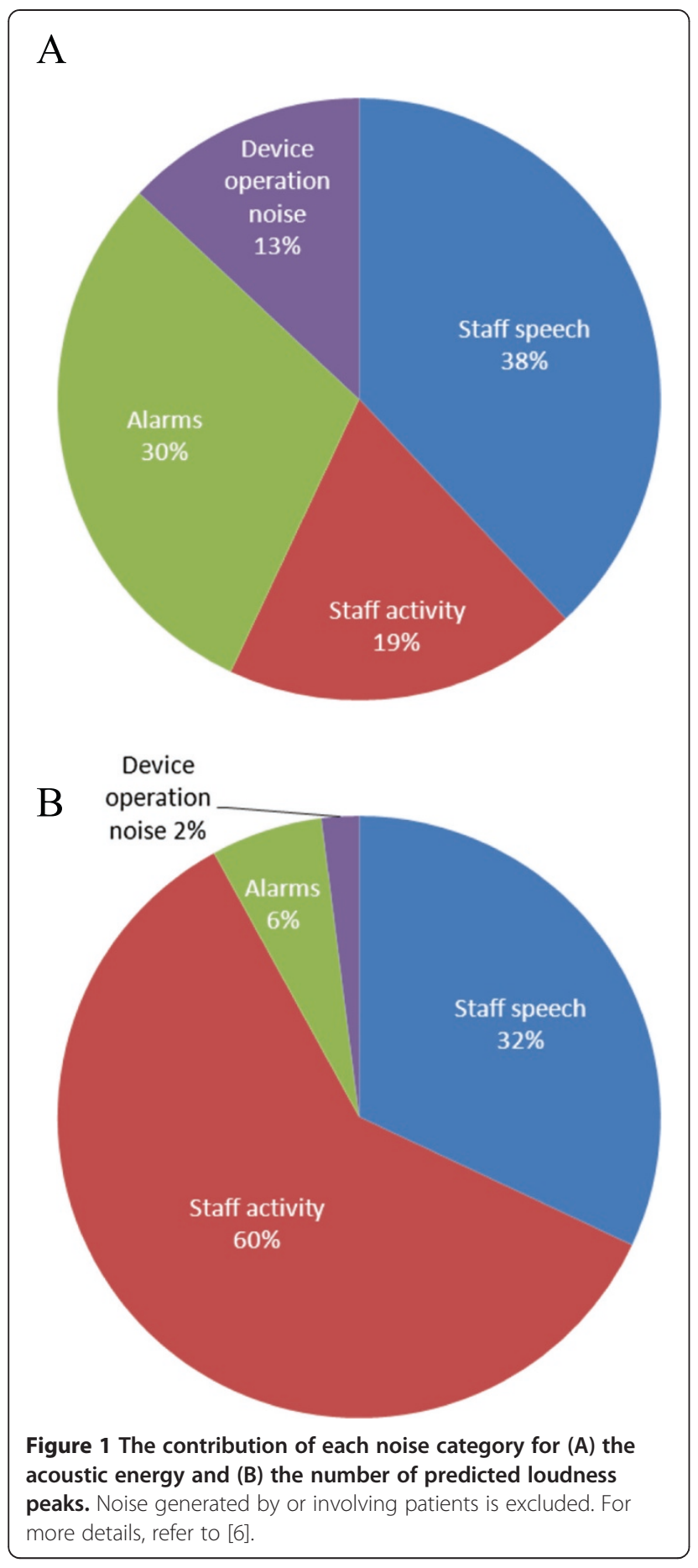

Published online: 27 August 2014

\section{References}

1. Darbyshire JL, Young JD: An investigation of sound levels on intensive care units with reference to the WHO guidelines. Crit Care 2013, 17:R187.

2. Ugras GA, Oztekin SD: Patient perception of environmental and nursing factors contributing to sleep disturbances in a neurosurgical intensive care unit. Tohoku J Exp Med 2007, 212:299-308.
3. Tegnestedt C, Gunther A, Reichard A, Bjurstrom R, Alvarsson J, Martling CR, Sackey P: Levels and sources of sound in the intensive care unit - an observational study of three room types. Acta Anaesthesiol Scand 2013, 57:1041-1050.

4. Hilton BA: Noise in acute patient care areas. Res Nurs Health 1985, 8:283-291.

5. Tsiou C, Eftymiatos D, Theodossopoulou E, Notis P, Kiriakou K: Noise sources and levels in the Evgenidion Hospital intensive care unit. Intensive Care Med 1998, 24:845-847.

6. Park M, Kohlrausch A, de Bruijn W, de Jager C, Simons K: Analysis of the soundscape in an intensive care unit based on the annotation of an audio recording. J Acoust Soc Am 2014, 135:1875-1886.

doi:10.1186/s13054-014-0493-

Cite this article as: Simons et al:: Noise pollution in the ICU: time to look into the mirror. Critical Care 2014 18:493. 